\title{
Cytochrome $P$-450 3A13 and endothelin jointly mediate ductus arteriosus constriction to oxygen in mice
}

Barbara Baragatti, Enrica Ciofini, Francesca Scebba, Debora Angeloni, Daria Sodini, Stefano Luin, Gian Michele Ratto, Virginia Ottaviano, Eleonora Pagni, Aldo Paolicchi, Simona Nencioni and Flavio Coceani

Am J Physiol Heart Circ Physiol 300:H892-H901, 2011. First published 30 December 2010;

doi:10.1152/ajpheart.00907.2010

You might find this additional info useful...

This article cites 25 articles, 12 of which can be accessed free at:

http://ajpheart.physiology.org/content/300/3/H892.full.html\#ref-list-1

Updated information and services including high resolution figures, can be found at:

http://ajpheart.physiology.org/content/300/3/H892.full.html

Additional material and information about AJP - Heart and Circulatory Physiology can be found at: http://www.the-aps.org/publications/ajpheart

This infomation is current as of March 6, 2011.

AJP - Heart and Circulatory Physiology publishes original investigations on the physiology of the heart, blood vessels, and lymphatics, including experimental and theoretical studies of cardiovascular function at all levels of organization ranging from the intact animal to the cellular, subcellular, and molecular levels. It is published 12 times a year (monthly) by the American

Physiological Society, 9650 Rockville Pike, Bethesda MD 20814-3991. Copyright @ 2011 by the American Physiological Society.

ISSN: 0363-6135, ESSN: 1522-1539. Visit our website at http://www.the-aps.org/. 


\title{
Cytochrome $P-4503 \mathrm{~A} 13$ and endothelin jointly mediate ductus arteriosus constriction to oxygen in mice
}

\author{
Barbara Baragatti, ${ }^{1,2 *}$ Enrica Ciofini, ${ }^{1 *}$ Francesca Scebba, ${ }^{1 *}$ Debora Angeloni, ${ }^{1,2 *}$ Daria Sodini, ${ }^{1}$ \\ Stefano Luin, ${ }^{3}$ Gian Michele Ratto, ${ }^{4}$ Virginia Ottaviano, ${ }^{5}$ Eleonora Pagni, ${ }^{1}$ Aldo Paolicchi, ${ }^{5}$ \\ Simona Nencioni, ${ }^{1}$ and Flavio Coceani ${ }^{1,2}$ \\ ${ }^{1}$ Scuola Superiore Sant'Anna and ${ }^{2}$ Institute of Clinical Physiology CNR, Pisa; ${ }^{3}$ Scuola Normale Superiore and ${ }^{4}$ Consiglio \\ Nazionale delle Ricerche, National Enterprise for nanoScience and nanoTechnology, Pisa; and ${ }^{5}$ Department of Experimental \\ Pathology, University of Pisa, Pisa, Italy
}

Submitted 13 September 2010; accepted in final form 22 December 2010

Baragatti B, Ciofini E, Scebba F, Angeloni D, Sodini D, Luin S, Ratto GM, Ottaviano V, Pagni E, Paolicchi A, Nencioni S, Coceani F. Cytochrome $P-4503 \mathrm{~A} 13$ and endothelin jointly mediate ductus arteriosus constriction to oxygen in mice. Am J Physiol Heart Circ Physiol 300: H892-H901, 2011. First published December 30, 2010; doi:10.1152/ajpheart.00907.2010.-The fetal ductus arteriosus (DA) contracts to oxygen, and this feature, maturing through gestation, is considered important for its closure at birth. We have previously obtained evidence of the involvement of cytochrome $P-450$, possibly of the 3A subfamily (CYP3A), in oxygen sensing and have also identified endothelin (ET)-1 as the attendant effector for the contraction. Here, we examined comparatively wild-type (WT) and CYP3Anull $\left(\right.$ Cyp $\left.3 a^{-1-}\right)$ mice for direct validation of this concept. We found that the CYP3A subfamily is represented only by CYP3A13 in the WT DA. CYP3A13 was also detected in the DA by immunofluorescence microscopy, being primarily colocalized with the endoplasmic reticulum in both endothelial and muscle cells. However, a distinct signal was also evident in the plasma membrane. Isolated DAs from term WT animals developed a sustained contraction to oxygen with transient contractions superimposed. Conversely, no tonic response occurred in Cyp3a $a^{-1-}$ DAs, whereas the phasic response persisted unabated. Oxygen did not contract the preterm WT DA but caused a full-fledged contraction after retinoic acid (RA) treatment. RA also promoted an oxygen contraction in the Cyp3a $a^{-/-}$DA. However, responses of RA-treated WT and Cyp3a $a^{-1-}$ mice differed in that only the former abated with ET-1 suppression. This implies the existence of an alternative target for RA responsible for the oxygen-induced contraction in the absence of CYP3A13. In vivo, the DA was constricted in WT and Cyp $3 a^{-1-}$ newborns, although with a tendency to be less narrowed in the mutant. We conclude that oxygen acts primarily through the complex CYP3A13 (sensor)/ET-1 (effector) and, in an accessory way, directly onto ET-1. However, even in the absence of CYP3A13, the DA may close postnatally thanks to the contribution of ET-1 and the likely involvement of compensating mechanism(s) identifiable with an alternative oxygen-sensing system and/or the withdrawal of relaxing influence(s) operating prenatally.

oxygen sensing; development; retinoic acid; fetal and neonatal physiology

THE DUCTUS ARTERIOSUS (DA) is a fetal shunt connecting the pulmonary artery with the aorta and allowing blood to bypass the unexpanded lungs. At birth, with the onset of lung ventilation and the attendant rise in blood oxygen tension $\left(\mathrm{PO}_{2}\right)$, the

* B. Baragatti, E. Ciofini, F. Scebba, and D. Angeloni contributed equally to this work.

Address for reprint requests and other correspondence: F. Coceani, Scuola Superiore Sant'Anna, Piazza Martiri della Libertà 33, Pisa 56127, Italy (e-mail: coceani@sssup.it) vessel constricts and eventually closes. The distinctive sensitivity of DA muscle cells to oxygen is developmentally regulated and matures more slowly compared with contractile function (20). In fact, the preterm DA may contract little, or not at all, to oxygen while presenting a fairly well-expressed response to conventional spasmogens $(1,20,27)$. Significantly, retinoic acid (RA) promotes maturation of the susceptibility to oxygen (27), and this action, although not yet defined in its underlying mechanism, represents a useful tool for the study of the oxygen-sensing system.

The identity of the DA oxygen sensor has been intensely investigated through the years. We have previously assigned this function to a cytochrome P-450 (CYP450) hemoprotein, tentatively associated with the $3 \mathrm{~A}$ subfamily (CYP3A), operating as a catalytic element in a monooxygenase reaction. Supporting our scheme is the effectiveness of carbon monoxide and a host of CYP450 inhibitors in curtailing the oxygeninduced constriction (5). Coincidentally, we have found an effector in endothelin (ET)-1, with the prime evidence being the curtailment of the oxygen response upon ET-1 suppression $(7,8)$ and the opposing action of oxygen (stimulation) versus carbon monoxide (inhibition) on ET-1 release $(5,6) .{ }^{1}$ Intrinsic in our scheme is also the idea that a hitherto-uncharacterized, CYP3A-based monooxygenase product serves as the messenger from the sensor to the effector. Another group (22) has reached our same conclusion on the central role of ET-1 in the DA constriction to oxygen. Alternatively, the sensing function has been identified with a set of voltage-gated $\mathrm{K}^{+}\left(\mathrm{K}_{\mathrm{V}}\right)$ channels, $\mathrm{K}_{\mathrm{v}} 1.5$ and $\mathrm{K}_{\mathrm{v}} 2.1$, being inhibited by oxygen and causing through the attendant depolarization an activation of voltagedependent L-type and T-type $\mathrm{Ca}^{2+}$ channels $(2,12,23)$. Even the latter scheme, however, recognizes a contribution of ET-1 to the oxygen effect either as a key element in the activation sequence (13) or as a reinforcing mechanism to $K_{v}$ channel operation (12). Here, we prove the mediator function of CYP3A, specifically the mouse isoform CYP3A13, in DA constriction to oxygen, and we also validate the concept of a

\footnotetext{
${ }^{1}$ Our data are at variance with a report by Michelakis et al. (15) showing no effect of oxygen on ET-1 formation in the DA. However, this result was obtained in surgical specimens from infants as opposed, in our case, to DAs from term fetal lambs being exposed for the first time to oxygen stimulation. Basal values of ET-1 release were severalfold higher with the neonatal DA and, while a methodological factor inherent to the species or the assay procedure cannot be excluded, the difference may also be ascribed to the special character of the vessel and intervening manipulations before surgery. In the latter event, a distinct ET-1 rise due to oxygen might have been obscured by a larger pool of the compound originating from nonrelevant sources.
} 
linkage of this hemoprotein with ET-1 in ensuring a fullfledged response.

\section{MATERIALS AND METHODS}

Mice. Animals were housed in temperature- and humidity-controlled quarters, with constant 12:12-h light-dark cycles, and were given food and water ad libitum. Surgical procedures and experimental protocols were approved by the Animal Care Committee of the Ministry of Health. We used CYP3A-null $\left(\mathrm{Cyp} 3 \mathrm{a}^{-\prime-}\right)$ mice of the FVB strain (courtesy of Dr. A.H. Schinkel) (11) and verified the absence of CYP3A13 by RT-PCR. C57BL/6 and FVB mice (Harlan, San Pietro al Natisone, Italy) served as wild-type (WT) controls after confirming that their DA responded similarly to oxygen.

Solutions and drugs. We used the following Krebs medium (in $\mathrm{mM}$ ): $118 \mathrm{NaCl}, 4.7 \mathrm{KCl}, 1.0 \mathrm{KH}_{2} \mathrm{PO}_{4}, 0.9 \mathrm{MgSO}_{4}, 2.5 \mathrm{CaCl}_{2}, 11.1$ dextrose, and $25 \mathrm{NaHCO}_{3}$. Solutions were bubbled with gas mixtures containing either no oxygen or oxygen in various concentrations $(2.5 \%, 12.5 \%, 30 \%$, and $95 \%)$ plus $5 \% \mathrm{CO}_{2}$ and balance nitrogen, with the intent of duplicating the fetal $(2.5 \%$ oxygen $)$ and neonatal (from $12.5 \%$ oxygen upward) conditions. Oxygen was required at concentrations exceeding the physiological range for maximal contraction (8), likely as a consequence of its steep transmural gradient even with a small-size vessel (10). We measured $\mathrm{PO}_{2}$ with a Chiron gas analyzer (model 248, Halstead, UK) and found values of $7.31 \pm$ $0.01 / 0.95 \pm 0.002,16.6 \pm 0.07 / 2.16 \pm 0.009,37.2 \pm 0.6 / 4.84 \pm$ $0.08,152 \pm 1 / 19.7 \pm 0.2$, and $633 \pm 2 / 82.3 \pm 0.2 \mathrm{mmHg} / \mathrm{kPa}(\mathrm{pH}$ $7.39 \pm 0.003$ ) with $0 \%, 2.5 \%, 12.5 \%, 30 \%$, and $95 \%$ oxygen mixtures, respectively.

We selected a synthetic peptide as an antigen to prepare a polyclonal antibody against mouse CYP3A13 in the rabbit (custom generated by Primm, Milano, Italy). This peptide (amino acids 325-336: $\mathrm{NH}_{2}$-PDVQKKLQDEID-COOH) was selected within regions of maximal antigenicity in the CYP3A13 sequence (GenBank NP_031845), avoiding regions with potential posttranslational modifications or with homology to other agents. We confirmed the specificity of the antibody by dot blot on a nitrocellulose membrane (Hybond, Amersham, Buckinghamshire, UK) using the antigenic peptide in increasing concentrations until saturation. The signal was detected with a chemiluminescent substrate (Super Signal West Pico, Thermoscientific, Waltham, MA) and recorded on Kodak Biomax XAR film (Sigma, St. Louis, MO). Nevertheless, our antibody still elicited a faint immunostaining in the $C y p 3 a^{-1-} \mathrm{DA}$, and this feature was shared by a commercial antibody (CR3310, Biotrend Chemikalien, Cologne, Germany) reportedly selective for mouse CYP3A11 and CYP3A13 (data not shown). Polyclonal ET-1 and ET-converting enzyme (ECE)-1 antibodies were obtained from Santa Cruz Biotechnology (Santa Cruz, CA). We also used ET-1 (human/ porcine type, Peninsula, San Carlos, CA), the prostaglandin endoperoxide analog $9 \alpha, 11 \alpha$-epoxy-methano-15-hydroxy-prosta-5,13dienoic acid (U-44069; Cayman Chemical, Ann Arbor, MI), the thromboxane $\mathrm{A}_{2}\left(\mathrm{TXA}_{2}\right)$ analog 9,11-epithio-11,12-methano$\mathrm{TXA}_{2}$ (ONO-11113, courtesy of ONO Pharmaceutical, Osaka, Japan), retinoic acid (RA; all-trans-retinol palmitate; Sigma), and the ET-1/ET A receptor antagonist BQ-123 (Calbiochem, San Diego, CA). ET-1 was dissolved in sterile water with $0.05 \%$ human serum albumin $(100 \mu \mathrm{M})$, and aliquots of this stock solution were stored at $-20^{\circ} \mathrm{C}$ until use. U-44069 and ONO-11113 were dissolved in distilled ethanol $(0.1$ and $5 \mathrm{mg} / \mathrm{ml}$, respectively), and aliquots (stored at $-70^{\circ} \mathrm{C}$ ) were diluted with saline and Tris buffer ( $\left.\mathrm{pH} 7.4\right)$, respectively. RA was instead diluted in safflower seed oil.

In vitro recording. We carried out experiments in fetal mice, both term and preterm (at 19 and 17 days gestation, respectively), that had been delivered by Cesarean section under halothane anesthesia and killed by cervical dislocation. Selected experiments were also performed in the preterm animal whose mother had been treated with RA ( $1 \mathrm{mg} / \mathrm{kg}$, equivalent to $1,818 \mathrm{IU}$ ) by the intramuscular route for 3 consecutive days (4). The procedure for dissection of the ductus has been described in detail (8). Briefly, we secured the animal with its left side up in a chamber containing ice-cold Krebs solution gassed with $5 \% \mathrm{CO}_{2}$ in nitrogen. Through a thoracotomy, the ductus was exposed and separated from the adjoining large blood vessels. Once isolated, the vessel was suspended onto $25-\mu \mathrm{m}$ tungsten wires (Cooner, Chatsworth, CA) and placed inside an organ bath. The fluid was gassed with a mixture containing $2.5 \%$ oxygen, and the same gas mixture was flushed through a hood covering the bath. Preparations were then equilibrated $\left(\sim 60 \mathrm{~min}\right.$ at $\left.37^{\circ} \mathrm{C}\right)$ under minimum stretch (preterm/term: $0.05 \pm 0.001 / 0.09 \pm 0.003 \mathrm{mN} / \mathrm{mm}, n=26$ and 43, respectively), and the attendant internal circumference $\left(C_{0}\right)$, with the related resting dimensions (see Supplemental Material, Supplemental Table 1$),{ }^{2}$ served as a reference in selecting the appropriate load. Afterward, tension was applied to attain an operating circumference coinciding with the condition in vivo $\left(C_{45}\right.$, preterm $/ C_{50}$, term $0.36 \pm$ $0.004 / 0.44 \pm 0.005 \mathrm{mN} / \mathrm{mm}$ ). The actual experiment was started after a second 60 - to $120-\mathrm{min}$ period of equilibration.

We used distinct protocols to test oxygen and ET-1. In protocol 1 $(n=42)$, we assessed the capability of WT (C57BL/6 and FVB) and Cyp $3 a^{-1-}$ DAs to contract to oxygen over a range of concentrations $(12.5 \%, 30 \%$, and $95 \%)$. We carried out experiments in both preterm and term preparations and in preterm preparations from RA-treated animals. BQ-123 $(1 \mu \mathrm{M})$ was tested on some of these preparations. We used a similar design with ET-1 in protocol $2(n=27)$, limiting the WT control to the C57BL/6 strain and avoiding any test with BQ-123. ET-1 was tested in cumulative concentrations $(0.1-300 \mathrm{nM})$ using 3- to 10-fold increments. In either protocol, ONO-11113 (0.1 $\mu \mathrm{M})$ and, in some experiments, U-44069 $(0.3 \mu \mathrm{M})$ provided a reference for maximal contraction. For analysis of responses, we considered as baseline the net tension (i.e., total tension minus applied

\footnotetext{
${ }^{2}$ Supplemental Material for this article is available at the American Journal of Physiology-Heart and Circulatory Physiology website.
}

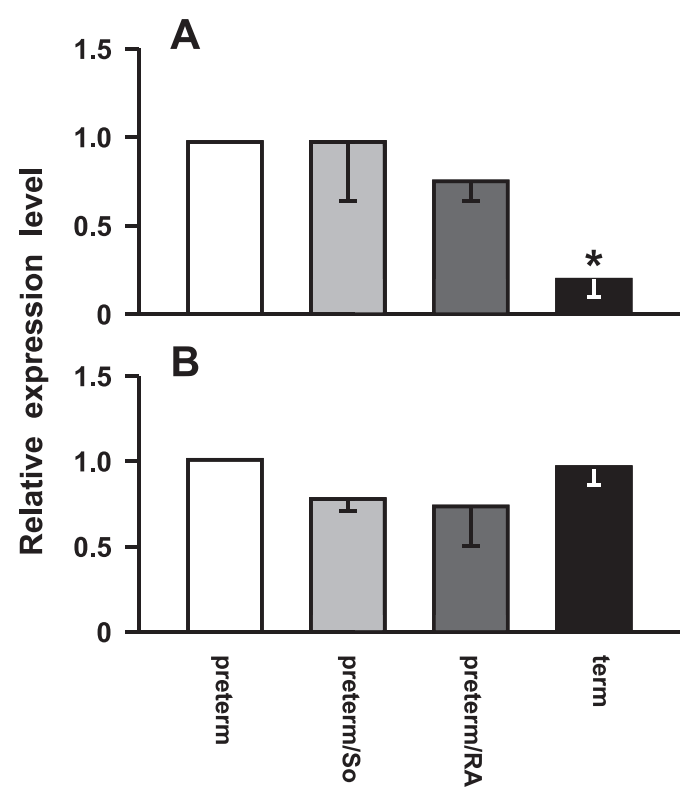

Fig. 1. Expression of cytochrome $P-4503 \mathrm{~A} 13$ (CYP3A13) mRNA $(A)$ and endothelin (ET)-1 mRNA $(B)$ in the ductus arteriosus (DA) of untreated preterm and term mouse fetuses and preterm fetuses treated with retinoic acid (RA) or its vehicle [safflower oil (So)]. The relative level by quantitative RT-PCR is given against expression data from the untreated preterm DA (value $=1$ ). Data are means $\pm \mathrm{SE} ; n=5$ except for the vehicle control, where $n=3$ and 4 in $A$ and $B$, respectively). $* P=0.027$ relative to the vehicle control (by ANOVA followed by the Bonferroni test). 
tension) developed by the preparation before any treatment. Effects of constrictors were measured by the rise in tension over baseline and were expressed in absolute values. Unless otherwise specified, experiments were carried out at $2.5 \% \mathrm{O}_{2}$.

Gene expression analysis. We pooled DA specimens from term and preterm (without/with RA pretreatment) fetuses in distinct groups (30-40 animals/group) according to the experimental condition. The adult liver or kidney was used as reference, depending on the gene. Total RNA was isolated (3) with Tripure isolation reagent (Roche, Indianapolis, IN), and its yield was measured spectrophotometrically. DNase I (Roche)-treated RNA was reverse transcribed with 1 unit of thermoscript RT (Invitrogen, Carlsbad, CA) in the presence of hexanucleotide primers. The cDNA product ( 0.1 or $0.2 \mu \mathrm{g} /$ group) was used for amplification in semiquantitative and then comparative realtime PCR for selected genes. Primer sequences were retrieved from the literature or were designed on purpose for the former analysis (see Supplemental Table 2), whereas the latter used an online library (Applied Biosystems, Foster City, CA). For semiquantitative analysis, electrophoresis of PCR products was performed on agarose gels [1.5\% (wt/vol)] stained with ethidium bromide, and bands from the DA and a reference organ were visualized in parallel. Quantitative real-time PCRs (40 cycles) were performed on an ABI Prism 7700 instrument using TakMan Universal PCR mastermix (Applied Biosystems). We quantified gene expression in triplicate by the comparative threshold cycle method (ABI Prism Relative Quantification Software, Applied Biosystems) using $\beta$-actin as a reference.

Immunohistochemistry. We prepared serial, transversal sections (5 $\mu \mathrm{m}$ thick) of frozen DAs in embedding medium (OCT, Sakura Finetek, Torrance, CA). Sections were fixed in cold acetone (10 min at $-20^{\circ} \mathrm{C}$ ) and, for antigen retrieval, were immersed in citrate buffer (0.01 M, pH 6.0) for a 15-min treatment in a microwave oven. The resulting specimens were kept in goat (CYP3A13, ECE-1) or chicken (ET-1) serum $[10 \%(\mathrm{vol} / \mathrm{vol})]$ for $1 \mathrm{~h}$ at room temperature and were subsequently incubated overnight with CYP3A13, ET-1, or ECE-1 antibody (dilution 1:50, 1:25, and 1:100, respectively) at $4^{\circ} \mathrm{C}$. Goat anti-rabbit $\lg$ (CYP3A13, 1:250 and ECE-1, 1:50; Zymed, Carlsbad, CA) or chicken anti-goat lgG (ET-1, 1:300; Santa Cruz), both conjugated to FITC, served as the secondary antibody. Specificity of binding was verified by omitting the primary antibody. We determined the colocalization of immunoreactive sites with the plasma membrane and endoplasmic reticulum using, respectively, the markers wheat germ agglutinin conjugates marine blue and BODIPY 558/568 Brefeldin A (Molecular Probes, Eugene, OR). Slides were protected with an anti-fading agent (Vectashield, Vector, Burlingame, $\mathrm{CA}$ ), and images were acquired on a fluorescence (model DMR, Leica) or confocal (TCS-SP2 on model DM IRE 2, Leica) microscope. We confirmed the colocalization of signals in both the plasma membrane and endoplasmic reticulum by building a three-dimensional (3-D) picture from serial images through the $z$-axis (deconvolution technique) (14). Voxel dimensions were chosen to satisfy the Nyquist criterion based on the experimental point spread function, and the point spread function was measured with 500-nm spherical beads (TetraSpeck, Molecular Probes). No appreciable photobleaching was noted during image acquisition. We used Huygens Professional 3.2.0p7 software (Scientific Volume Imaging, Hilversum, The Netherlands) to calculate the Pearson coefficient documenting the presence (value, 0 to +1 ) or absence (value, 0 to -1 ) of colocalization. The
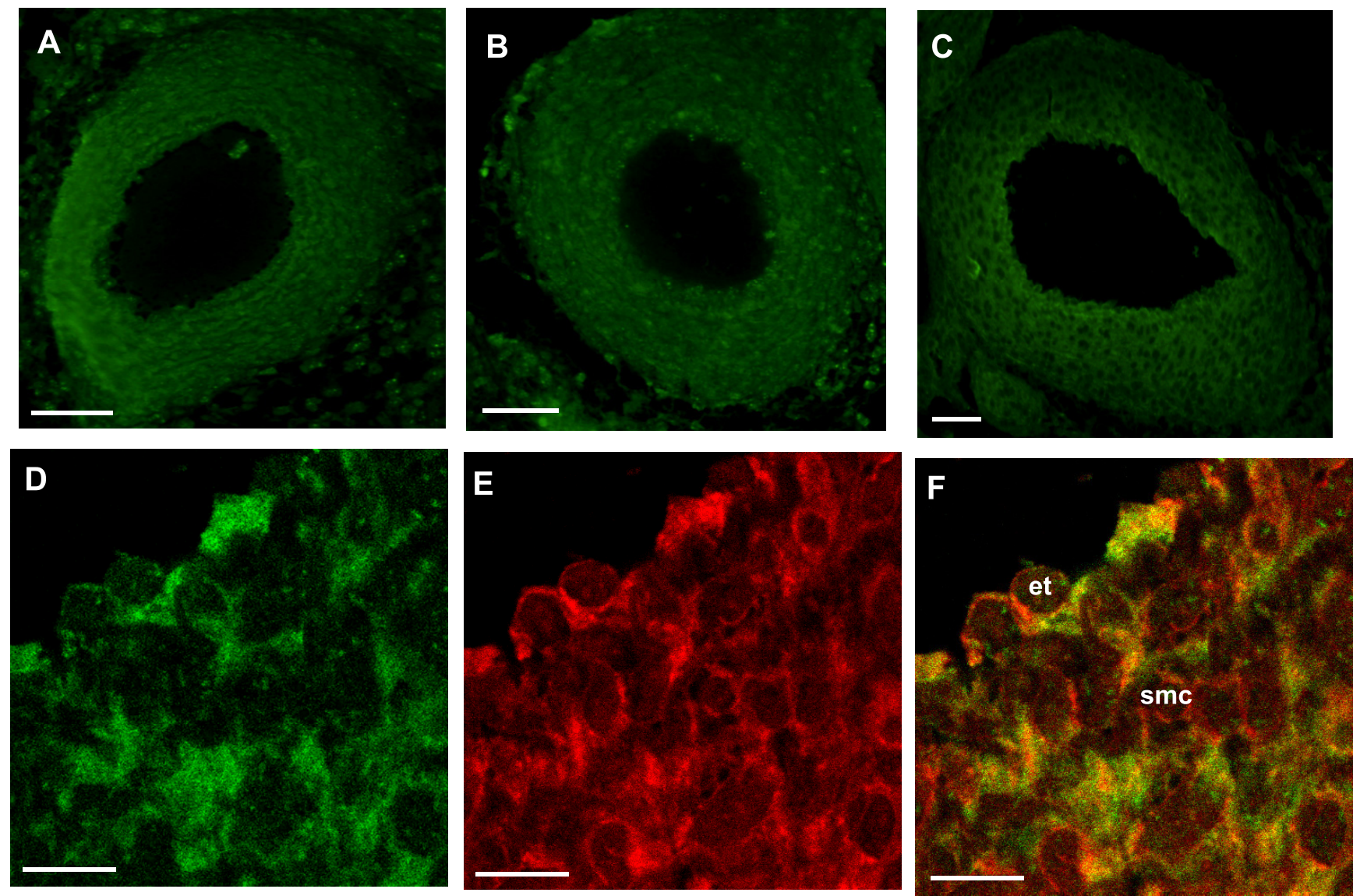

Fig. 2. Immunofluorescence micrographs of the mouse DA. A-C: epifluorescence images of sections incubated with CYP3A13 antibody. A: preterm DA; $B$ : RA-treated preterm DA; $C$ : term DA. $D-F$ : confocal images of sections stained in sequence with CYP3A13 antibody $(D)$, the endoplasmic reticulum marker $(E)$, and the two superimposed $(F)$. et, Endothelium; smc, smooth muscle. Scale bars $=50 \mu \mathrm{m}$ for $A-C$ and $10 \mu \mathrm{m}$ for $D-F$. 
same software afforded an overlap colocalization map in the form of isolocalization surfaces.

Cell culture and $\mathrm{Ca}^{2+}$ imaging. We cultured DA muscle cells to measure changes in the cytosolic $\mathrm{Ca}^{2+}$ concentration $\left(\left[\mathrm{Ca}^{2+}\right]_{i}\right)$ in response to oxygen. Endothelium-denuded WT and $C y p 3 a^{-1-}$ term vessels were prepared for this purpose using a procedure that has been previously described and validated $(3,24)$. They were then placed in $5 \mathrm{ml}$ of Dulbecco's modified medium supplemented with $0.25 \mathrm{M}$ dextrose and $2 \mathrm{mg} / \mathrm{ml}$ collagenase (Clostridium histolyticum type I, Sigma). After an incubation at $37^{\circ} \mathrm{C}$ for $30 \mathrm{~min}$, the tissue suspension was centrifuged (170 $\mathrm{g}, 5 \mathrm{~min})$, and the resulting cell pellet was resuspended in $1 \mathrm{ml}$ of Dulbecco's modified medium containing 10\% FBS and a combination of penicillin $(100 \mathrm{U} / \mathrm{ml})$ and streptomycin $(0.1$ $\mathrm{mg} / \mathrm{ml}$ ). Dispersed cells were then plated onto a 35/12-mm glass dish (Willco Wells, Amsterdam, The Netherlands) and were incubated at $37^{\circ} \mathrm{C}$. Medium was replaced after $24 \mathrm{~h}$, and the operation was repeated at 48-h intervals. Cells were studied after 3-8 days once they had grown to a subconfluent monolayer. Their identity was confirmed with an antibody against $\alpha$-actin (Sigma). We assessed changes in cell $\mathrm{Ca}^{2+}$ levels due to oxygen from the fluorescence signal ratio between $\mathrm{Ca}^{2+}$-sensitive fluo-4 AM (Invitrogen) and $\mathrm{Ca}^{2+}$-insensitive 5-(and 6)-carboxy snarf-1 (SNARF; Invitrogen). SNARF was used to correct for focus shifts and mechanical artefacts that may occur with pro- longed recording. The recording solution had the following composition (in $\mathrm{mM}$ ): $130 \mathrm{NaCl}, 3.1 \mathrm{KCl}, 2.0 \mathrm{CaCl}_{2}, 1.0 \mathrm{MgCl}_{2}, 5.0$ dextrose, $1.0 \mathrm{~K}_{2} \mathrm{HPO}_{4}, 4.0 \mathrm{NaHCO}_{3}, 10 \mathrm{HEPES} / \mathrm{NaOH}, 1.0$ ascorbic acid, 0.5 myoinositol, 2.0 pyruvic acid, and 0.02 ( \pm )-sulfinpyrazone ( $\mathrm{pH}$ 7.2-7.4). Before dye loading, cell-bearing dishes were washed with warm, serum-free recording solution and were incubated for 20 $\min$ at $37^{\circ} \mathrm{C}$. They were then placed in the loading medium, which consisted of $10 \mu \mathrm{M}$ fluo- 4 and $9 \mu \mathrm{M}$ SNARF in a pluronic acid (20\%)-DMSO $(0.002 \%)$ mixture. Treatment (at $37^{\circ} \mathrm{C}$ ) continued for $15 \mathrm{~min}$, and after three washings, cells were returned to the recording solution for a 30-min period. Afterward, cells were transferred to a temperature-controlled $\left(37^{\circ} \mathrm{C}\right)$, humidified chamber (PeCon, Erbach, Germany) through which a preheated $2.5 \% \quad \mathrm{O}_{2}-5 \% \quad \mathrm{CO}_{2}$-balance nitrogen mixture was passed for baseline recording. This mixture was replaced by $30 \% \mathrm{O}_{2}-5 \% \mathrm{CO}_{2}$-balance nitrogen at the 40 -min mark, and responses of WT versus Cyp3 $a^{-1-}$ cells were examined comparatively. The oxygen concentration was selected from experiments in the isolated vessel where it produces a near-maximal contraction (see below). Imaging was performed at 30-s intervals on an inverted confocal microscope (TCS-NT, Leica) equipped with a $\times 40$ magnification oil-immersion lens. Dye excitation was provided by a $488-\mathrm{nm}$ wavelength from an ArKr laser and was read in the fluorescein and rhodamine spectral bands for fluo-4 and SNARF, respectively. A total

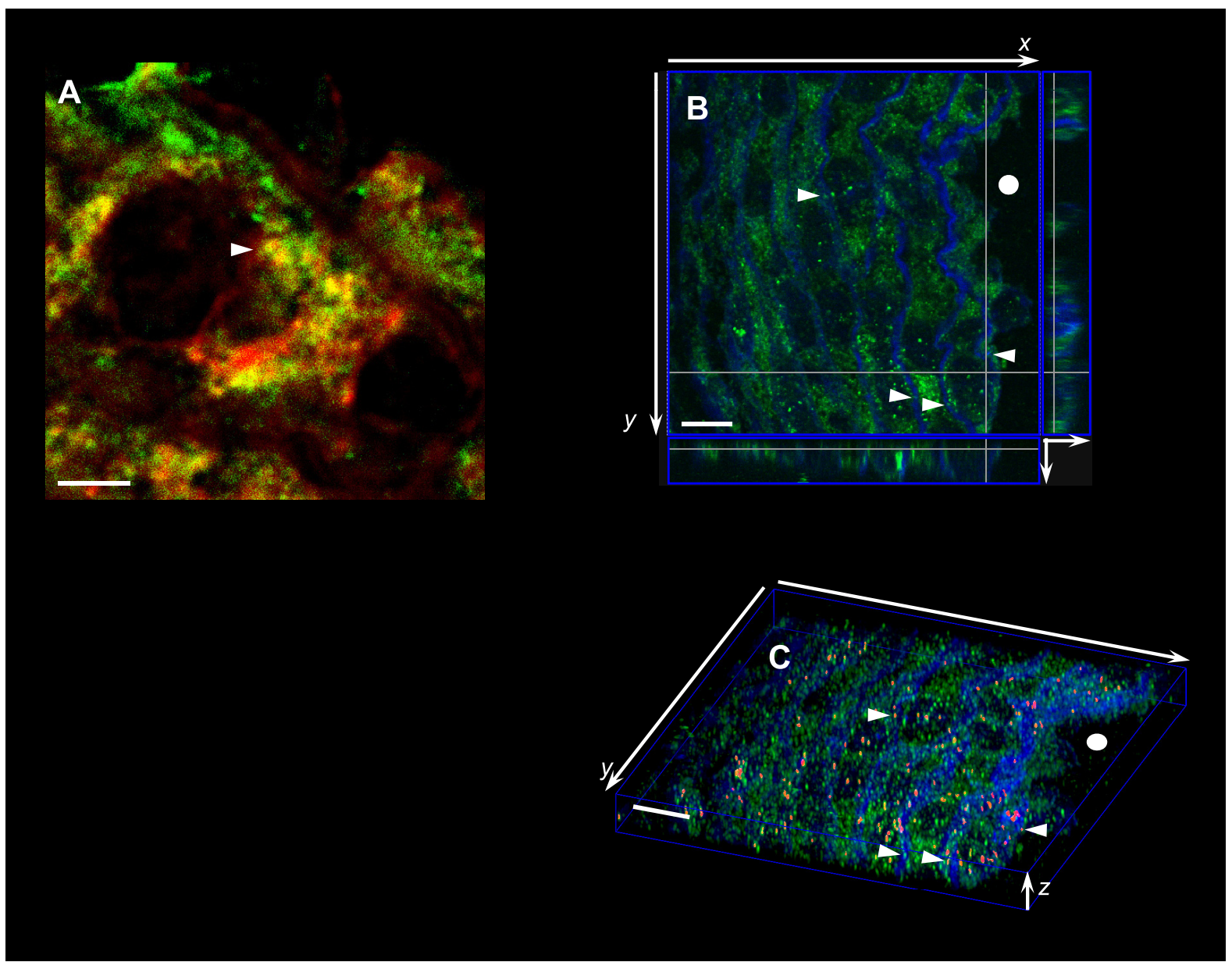

Fig. 3. Subcellular localization of CYP3A13 in the mouse DA. A: high-power colocalization (arrowhead) of CYP3A13 immunostaining with the endoplasmic reticulum. $B$ and $C$ : colocalization of CYP3A13 immunostaining with the plasma membrane marker as evident from the deconvolution of $z$-stacks (close circle, vessel lumen). $B$ : image from $x y$ scanning at a fixed value of $z$ (horizontal and vertical lines are the intersections of the other two planes) with $x z$ (bottom box) and $y z$ (right box) sections referring to the entire stack. $C$ : three-dimensional maximum intensity projection-rendered image from deconvolved $z$-stacks shown in $B$ with isolocalization sites appearing in red. Arrowheads indicate corresponding regions in $B$ and $C$ with examples of colocalization. Note that Pearson coefficient for the group was $0.095 \pm 0.014 ; n=5$ [coefficient for the CYP3A-null $\left(\right.$ Cyp $\left.3 a^{-1-}\right)$ DA was $-0.028 \pm 0.012, n=3$; data not shown]. Scale bars $=5$ $\mu \mathrm{m}$ for $\mathrm{A}$ and $10 \mu \mathrm{m}$ for $B$ and $C$. 
of 30-90 cells (average: 50 cells) were studied in each experiment using National Institutes of Health (NIH) ImageJ (Bethesda, MD) software for image analysis and quantification.

In vivo experiments. We used term fetuses (19 days gestation) delivered by Cesarean section under halothane anesthesia and newborns at $3 \mathrm{~h}$ after vaginal delivery. Fetuses were also obtained from dams that had been made hyperoxic (3-h exposure to $100 \% \mathrm{O}_{2}$ ) with the intent of studying separately the effect of oxygen alone versus birth (8). We assessed the DA caliber in fetuses (normoxic and hyperoxic) and newborns, both WT and $C y p 3 a^{-1-}$, with the whole body freezing technique (8). This technique provides a faithful image of the condition in vivo, as verified by us in several experimental models where the DA was either constricted or overdilatated. Briefly, transversal sections ( $5 \mu \mathrm{m}$ thick), progressing serially through the whole length of the frozen DA, were obtained and stained with $1 \%$ methylene blue. We photographed each section with a chargedcoupled device solid-state camera (COHU, San Diego, CA) and measured lumen area with the NIH ImageJ program. Both maximal and minimal values were retrieved from each series for computation.

Statistical analysis. Data are presented as means \pm SE. We calculated $P$ values with Student's $t$-test or ANOVA followed by the Bonferroni or Tukey tests. $P$ values of $<0.05$ were considered as statistically significant.

\section{RESULTS}

Gene expression analysis. We detected only one CYP3A isoform, CYP3A13, among the several members of this subfamily (see Supplemental Table 2). The transcript was already evident in the preterm DA, and, in fact, its expression abated with advancing gestation (Fig. 1A). Likewise, a downward trend relative to the vehicle control was seen upon RA treatment (Fig. 1A). We also found ET-1, but, unlike CYP3A13, it was not affected by gestational age or RA (Fig. $1 B$ ).

Localization of CYP3A13, ECE-1, and ET-1. Using fluorescence microscopy, we found CYP3A13 immunostaining in the DA. Its distribution was diffuse, encompassing both intimal and medial layers, and did not show any obvious change with fetal age or RA treatment (Fig. 2, $A-C$ ). Furthermore, with the appropriate markers, we proved that the signal mainly colocalized with the endoplasmic reticulum (Figs. 2, $D-F$, and $3 A$ ). This finding was confirmed with the deconvolution technique and the demonstration of an appropriate value for the Pearson coefficient $(0.25 \pm 0.02, n=5$; data not shown). Some immunostaining was also located in the plasma membrane with a spot-like pattern, and the actual coincidence of the signal with this structure was verified in 3-D deconvoluted images (Fig. 3, $B$ and $C$ ). Equally diffuse was ECE-1 immunoreactivity, with its intensity remaining unchanged from preterm to term (Fig. 4, $A$ and $C$ ) but increasing instead in response to RA (Fig. 4, $A$ and $B$ ). Regardless of age, on the other hand, ET-1 was markedly expressed in the intimal layer and only moderately in the medial layer. RA, however, enhanced the signal within the media, thus making this immunostaining fairly uniform across the vessel wall (Fig. 4, $D-F$ ). In all cases, we did not detect any immunoreactivity in the absence of the primary antibody.
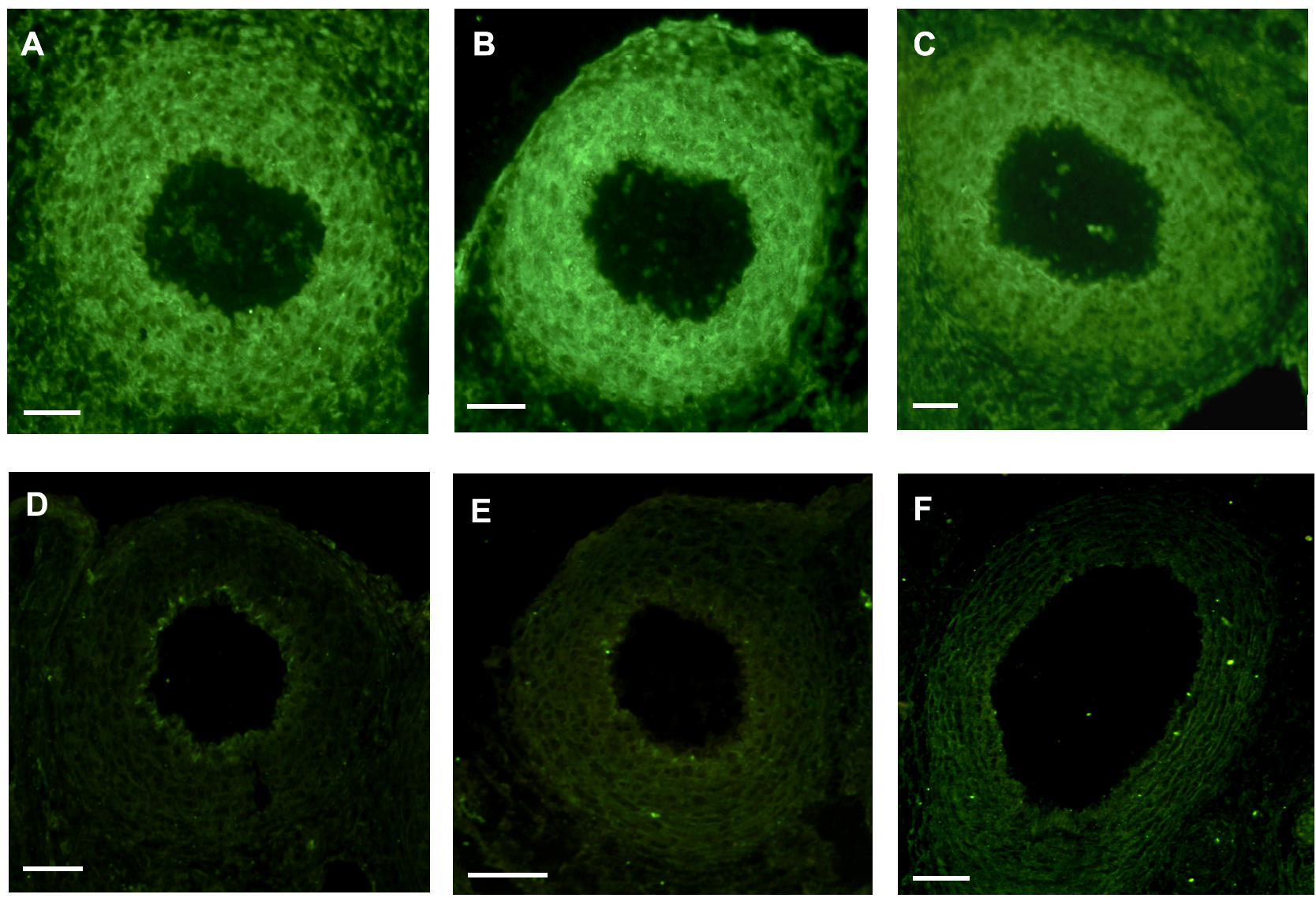

Fig. 4. Immunofluorescence micrographs of the mouse DA. Sections incubated with ET-converting enzyme (ECE)-1 (A-C) and ET-1 $(D-F)$ antibody. $A$ and $D$ : preterm DA; $B$ and $E$ : RA-treated preterm DA; $C$ and $F$ : term DA. Scale bars $=50 \mu \mathrm{m}$. 
A

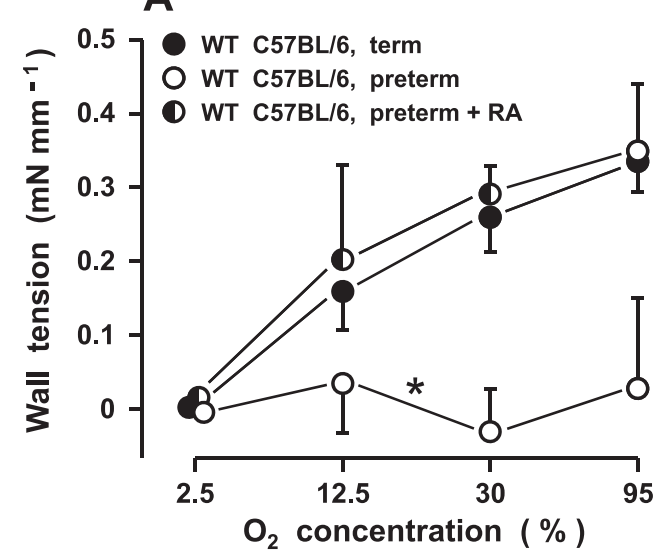

B

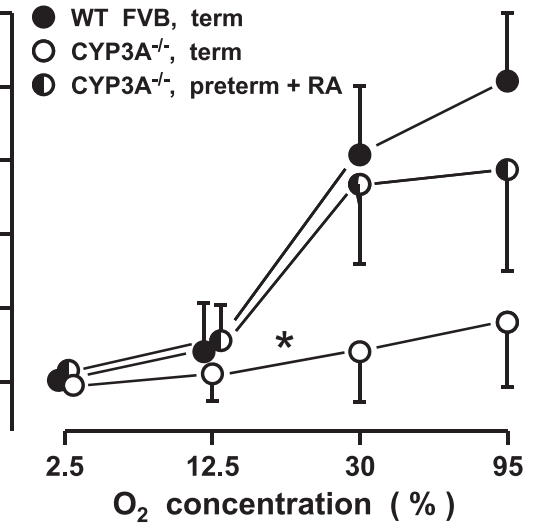

Fig. 5. Oxygen-induced contraction in the mouse DA: age and CYP3A dependence and activation by RA. $A$ : absence of the oxygen response in the preterm DA and its appearance upon RA treatment $(n=5$ or 6$)$. No response was seen in the untreated DA even when $95 \%$ oxygen was tested first (data not shown). $B$ : loss of the oxygen response with CYP3A deletion and its reversal by RA ( $n=5$ or 6 ). Note that the residual response in the Cyp3a-1- vessel did not reach significance relative to baseline at $2.5 \%$ oxygen. WT, wild type. ${ }^{*} P \leq 0.002$ vs. term or preterm DA plus RA treatment $(A) ; * P=0.014$ vs. the WT DA $(B)$ (by ANOVA followed by the Bonferroni test).
Isolated DA: contractile behaviour and response to oxygen and ET-1. Dimensions of the WT DA were greater in term than preterm animals and were consistent among strains (see Supplemental Table 1). At term, the vessel developed a variable degree of tension during equilibration $(0.1 \pm 0.02 \mathrm{mN} / \mathrm{mm})$ with transient contractions of uneven amplitude $(0.1-0.6 \mathrm{mN} /$ $\mathrm{mm}$ ) and/or low-amplitude fast discharges often superimposed. In contrast, the preterm DA presented barely any active tone $(0.05 \pm 0.02 \mathrm{mN} / \mathrm{mm})$ and only occasionally was its baseline record interrupted by a contractile event. The two age groups also differed in their response to reference spasmogen $(0.1 \mu \mathrm{M}$ ONO-11113 or $0.3 \mu \mathrm{M} \mathrm{U}-44069)$, with the contraction at term being about twice as high as that before term (1.02 \pm 0.07 and $0.63 \pm 0.05 \mathrm{mN} / \mathrm{mm}$, respectively). In agreement with a previous report (8), we observed a concentration-dependent contraction of the term DA to oxygen unfolding with episodes of tonic and phasic activity (Figs. 5, $A$ and $B$, and $6 A$ ). In contrast, the preterm DA did not contract to oxygen or contracted marginally only at the highest concentration (Fig. 5A). In fact, oxygen caused occasionally a modest relaxation instead of a contraction. Unlike oxygen, ET-1 had a similar effect in preterm and term preparations (Fig. $7 A$ ). In both cases, there was a progressively greater contraction from $\sim 0.1$ to $10-100$ $\mathrm{nM}$, with a subsequent reversal beyond this range.

We found the Cyp $3 a^{-1-}$ DA to differ from its WT counterpart in some respects. Its size tended to be smaller at term (see
Supplemental Table 1), and baseline tone was minimal or absent altogether $(0.02 \pm 0.01 \mathrm{mN} / \mathrm{mm})$. Nevertheless, the vessel still generated transient contractions, comparable in pattern with those of the WT, and also responded normally (term: $1.04 \pm 0.1 \mathrm{mN} / \mathrm{mm}$ ), or in a slightly reduced fashion (preterm: $0.37 \pm 0.03 \mathrm{mN} / \mathrm{mm}$ ), to a $\mathrm{TXA}_{2}$ mimic. Equally distinctive was its response to oxygen and ET-1. In the former case, the tonic component was virtually abolished (Fig. 5B), whereas transient contractions, whether slow (varying amplitude) or fast (low amplitude), persisted and presented, in fact, an acceleration through the test (Fig. 6B). ET-1, on the other hand, produced a contraction both at term and before term, but its response profile indicated lesser effectiveness (Fig. 7B).

RA promoted an oxygen response equally effectively in WT and Cyp $3 a^{-1-}$ animals. As shown in Fig. 5A, the preterm WT DA, which is normally unresponsive to oxygen, yielded after treatment a full-fledged contraction, overlapping that of the untreated term DA. Likewise, RA had an enabling effect on the preterm $C y p 3 a^{-1-}$ DA, although with a certain degree of variability over the entire oxygen range (Fig. $5 B$ ). In the WT $\mathrm{DA}$, the RA-induced oxygen response was reversed by the ET-1 antagonist BQ-123 (1 $\mu \mathrm{M}, n=4)$, and the residual contraction straddled threshold or was even replaced by a marginal relaxation (maximum: $-0.16 \mathrm{mN} / \mathrm{mm}$ ). Conversely, the equivalent response in the $C y p 3 a^{-1-}$ DA was suppressed by BQ-123 only in one of five experiments, whereas it devel-

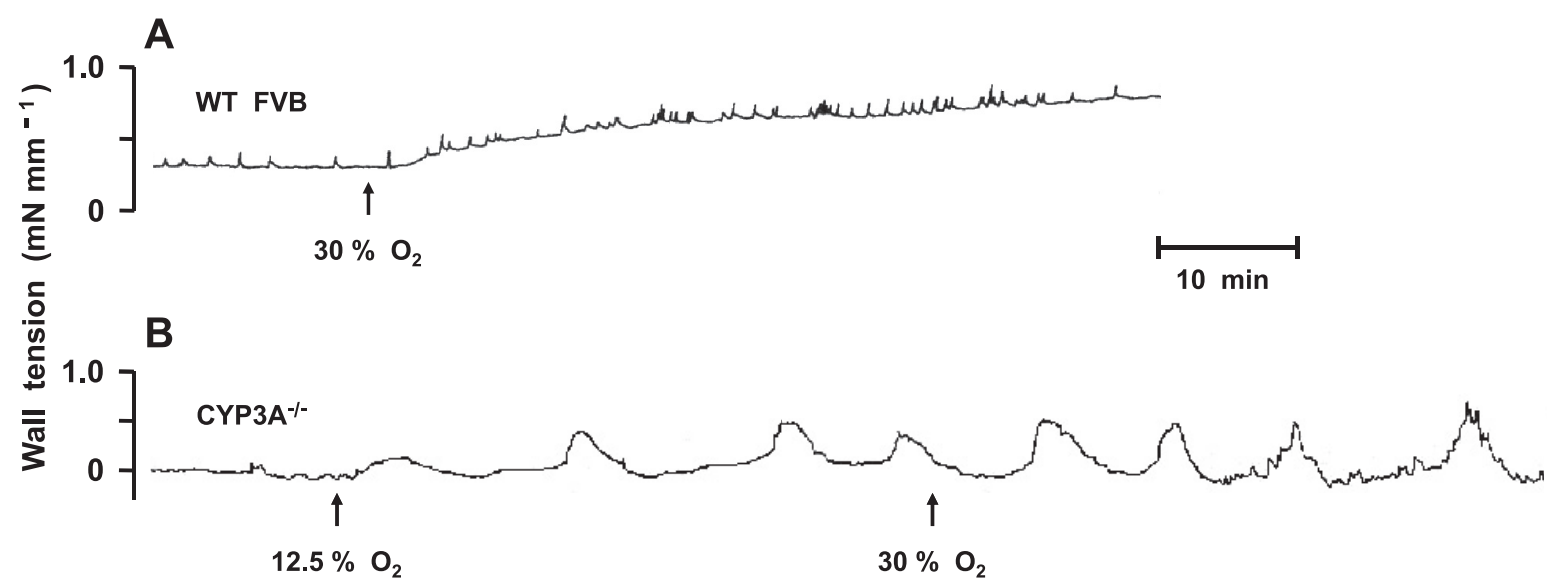

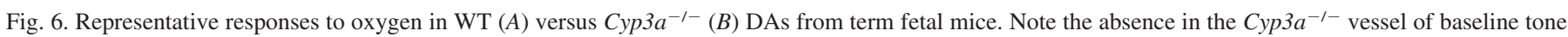
and sustained contraction to oxygen; only transient contractions showed an acceleration with the rise in oxygen tension (for details, see text). 
Fig. 7. Effect of ET-1 on DAs from preterm (both untreated and RA treated) and term mouse fetuses. A: WT DAs $(n=4-6)$ B: $C y p 3 a^{-1-}$ DAs $(n=4) . * P<0.0001$ vs. untreated $C y p 3 a^{-1-}$ DAs, both preterm and term (by ANOVA followed by the Bonferroni test). Note the lesser response of Cyp3a $a^{-1-}$ compared with WT DAs in either age group $(P=0.009$ and 0.004 at term and before term, respectively).

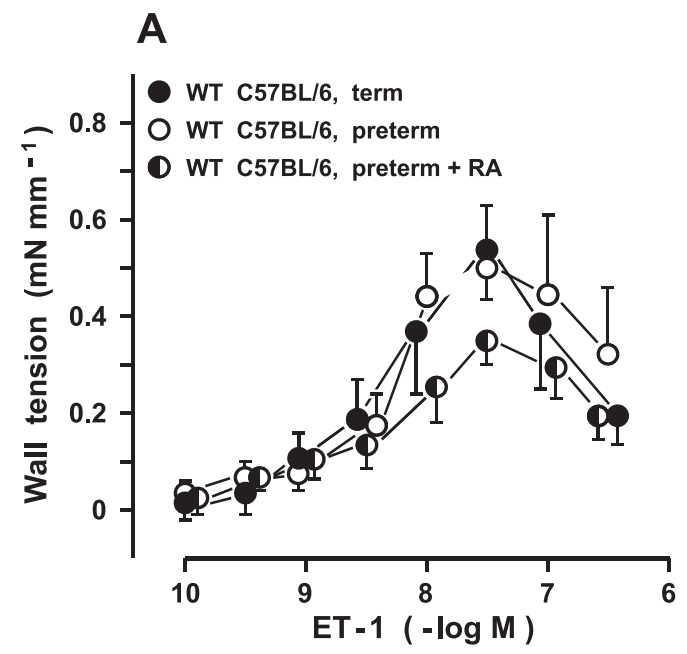

B

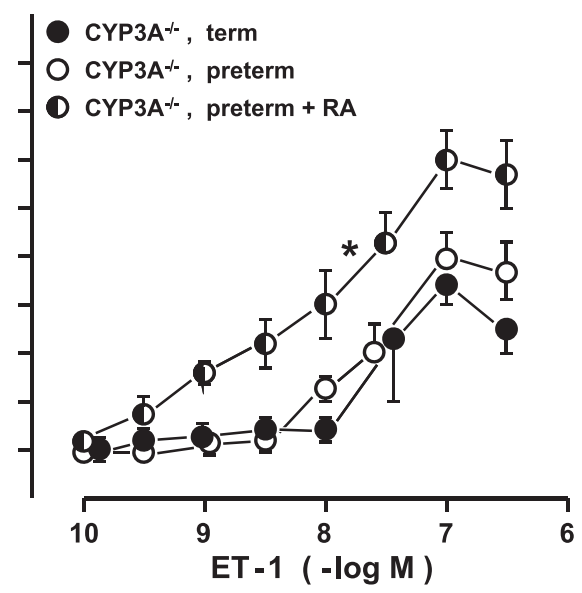

oped unabated in the remainder (maximal tension: $0.33 \pm 0.08$ $\mathrm{mN} / \mathrm{mm}, n=4)$. ET- 1 action on the preterm DA was also unevenly modified by RA depending on genotype. No change was seen in the WT vessel (Fig. 7A), whereas the attenuated response of $C y p 3 a^{-1-}$ increased to match that of the WT (Fig. 7B).

Effect of oxygen on $\left[\mathrm{Ca}^{2+}\right]_{i}$ in DA muscle cells. We recorded a stable $\left[\mathrm{Ca}^{2+}\right]_{\mathrm{i}}$ baseline in DA muscle cells (both WT and Cyp $3 a^{-1-}$ ) through exposure to $2.5 \%$ oxygen. Upon raising the oxygen concentration to $30 \%,\left[\mathrm{Ca}^{2+}\right]_{\mathrm{i}}$ of WT cells increased steadily in time without reaching a plateau over a 60 -min period (Fig. 8). No immediate response occurred with Cур $3 a^{-1-}$ cells, and a smaller upward trend was also observed with significance being reached only at the end of recording (Fig. 8).

In vivo experiments. We found a widely patent $\mathrm{DA}$ in the term fetus regardless of genotype (Fig. 9, $A$ and $B$ ). Maternal hyperoxia induced a modest constriction, not reaching significance in the WT fetus (Fig. 9A) and but becoming significant in the Cyp3a $a^{-1-}$ fetus (Fig. 9B). As expected, the DA constricted rapidly in the neonate, and at $3 \mathrm{~h}$ from delivery it was almost closed in either WT strain (Fig. 10A). We observed a comparable pattern in the Cyp $3 a^{-1-}$ newborn, although the vessel tended to be less narrowed (Fig. 10A). In addition, in

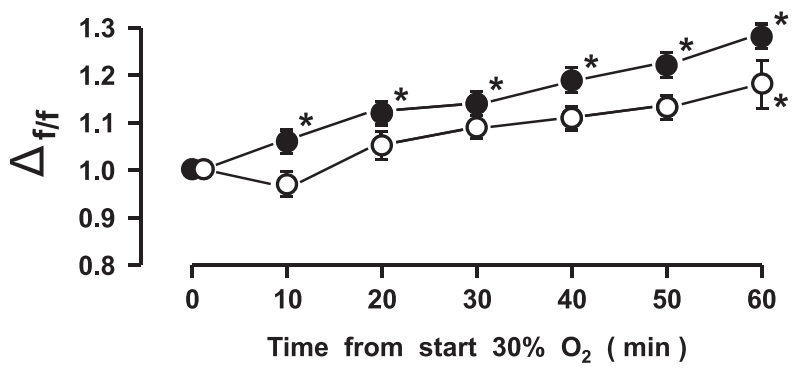

Fig. 8. Effect of oxygen on cytosolic $\mathrm{Ca}^{2+}$ in DA smooth muscle cells. WT (C57BL/6 strain; $\bullet$ ); Cyp3 $3 a^{-1-}(0)$. Cells were loaded with fluo-4 and SNARF (see MATERIALS AND METHODS), and recordings were made for $20 \mathrm{~min}$ at $2.5 \%$ oxygen before the switch (time 0 ) to $30 \%$ oxygen. Results are presented as the ratio of fluo-4 to SNARF divided by the baseline value at time $0\left(\Delta_{\mathrm{f} / \mathrm{f}}\right)$ Difference beween WT and Cyp $3 a^{-1-}$ curves: $P<0.001$ (by ANOVA; $n=$ 3 for both). $* P \leq 0.01$ vs. baseline $(\bullet) / P=0.005$ vs. baseline (O) (by ANOVA followed by the Tukey test). Note that baseline recording at $2.5 \%$ oxygen did not change with time in either cell type. any stage of the closing process, the inner lining of the Cyp $3 a^{-1-}$ DA appeared smoother and showed less of the intraluminal growth typical of the WT DA (Fig. 10B).

\section{DISCUSSION}

Our study proves that CYP3A13 is critical for the contraction of the isolated DA to oxygen, specifically for its sustained component. This conclusion, which accords with a host of earlier data (5), rests on three main findings: 1) loss of the tonic contraction to oxygen upon deletion of CYP3A coupled with the demonstration that CYP3A13 is the only member of this particular subfamily of CYP450 hemoproteins in the DA; 2) a reduced response to oxygen in DA muscle cells lacking CYP3A; and 3) the occurrence of CYP3A13 in DA muscle cells, with a distinct expression in the plasma membrane, where it is best positioned to sense oxygen changes against a steep transmural gradient (10). The role being proposed for CYP3A13 is closely intertwined with that assigned earlier to ET-1 since suppression of the latter, by pharmacological means $(7,22)$ or deletion of the $\mathrm{ET}_{\mathrm{A}}$ receptor subtype (8), also results in loss of the DA constriction to oxygen. Indeed, the importance of ET-1 is strengthened by our study insofar as the peptide is implicated in the ability of RA to promote ex novo an oxygen response in the preterm WT DA. We demonstrated, in fact, a reversal of RA action by the $\mathrm{ET}_{\mathrm{A}}$ antagonist BQ-123 and, in a complementary fashion, an enhanced immunoreactivity for ET-1 and its immediate synthetic enzyme ECE-1 upon RA treatment. However, outwardly incongruent with our data in vitro is the finding that, when hyperoxia was elicited in the mother, the $C y p 3 a^{-1-}$ DA constricted in utero similarly, or even more, compared with the WT DA. Furthermore, the DA closed almost normally in the Cyp $3 a^{-1-}$ newborn. Our discussion will address this particular issue and, coincidentally, the nature of the relationship between CYP3A13 and ET-1 in mediating the contraction to oxygen.

Earlier on, we proposed a scheme with a CYP450 hemoprotein as an oxygen sensor and ET-1 as an effector, with a hypothetical monooxygenase product being the messenger between the two. Our in vitro results, while giving an identity to the postulated sensor, are in accord with this arrangement and, furthermore, better qualify the role being played by ET-1. It is interesting to note in this connection the reduced responsive- 
A

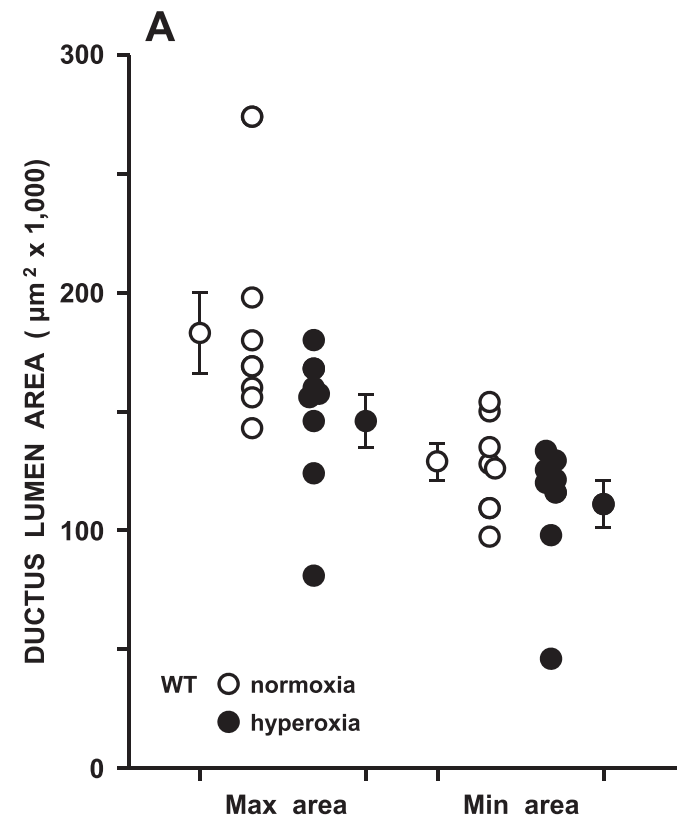

B

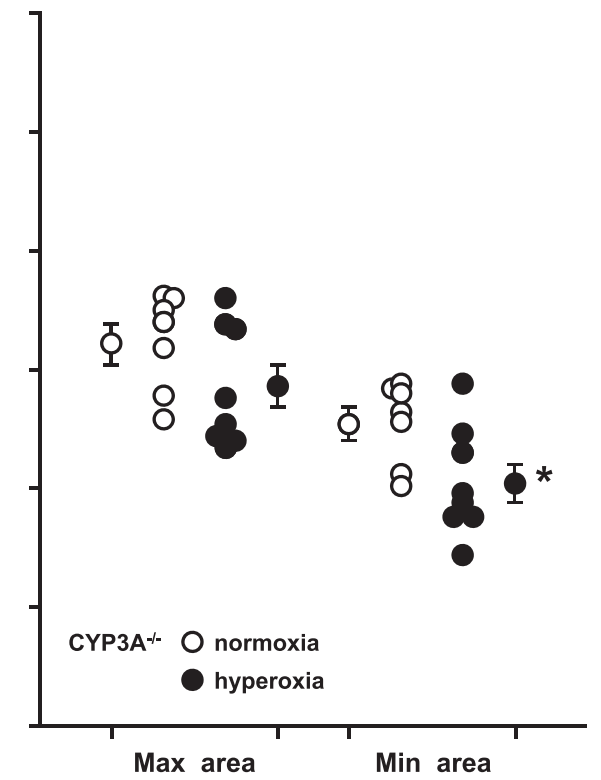

Fig. 9. Effect of maternal hyperoxia on the DA of term fetal mice. $A$ and $B$ : maximal and minimal DA cross-sectional areas for WT (C57BL/6 strain; A) and Cyp3a $a^{-1-}(B)$ DAs with each point representing a single experiment. $* P=0.032$ vs. the corresponding normoxic value (by Student's $t$-test). ness to ET-1 in the Cyp3a $a^{-1-}$ DA, implying that this oxygen effector is fully functional only with a viable sensor. However, a better appreciation of the relative contribution of CYP3A13 and ET-1 to the oxygen contraction emerges from the analysis of findings in their respective mutants. Significantly, we have found that any phasic event in the response to oxygen remains unchanged after CYP3A deletion, whereas $\mathrm{ET}_{\mathrm{A}}$ deletion results in the disappearance of both tonic and phasic components (8). From this, we can assume that the oxygen action on DA comprises two, mutually reinforcing, processes: a primary one involving in sequence CYP3A13 and ET-1 and ensuring a persistent rise in tone and an accessory one being exerted directly onto ET-1 and manifesting itself as the transient contractions over the baseline. Recognition of this dual modality for oxygen action has some consequences. It may account for the apparent divergence of findings in vitro and in vivo. Specifically, the occurrence of DA narrowing in the hyperoxic Cyp $3 a^{-1-}$ fetus, which, based on our scheme, could be ascribed to a direct activation of the ET- 1 system. ET- 1 could, in fact, produce this effect by itself and/or through a cascade of events being triggered by the increased motility of the vessel and the attendant disturbance in blood flow. Consistent with this concept is the finding that the hyperoxic stimulus is ineffective in the $\mathrm{ET}_{\mathrm{A}}$-null $\left(E T_{A}{ }^{-/-}\right)$fetus (8). In this context, one should also stress the peculiarities of the situation in vivo, particularly with a mutant, where overlapping or even latent mechanisms may come into play to compensate for the loss of the oxygen-sensing function. A relevant example is found in the $E T_{A}^{-1-}$ newborn, where the DA closes normally despite the absence of the oxygen-sensing mechanism (see

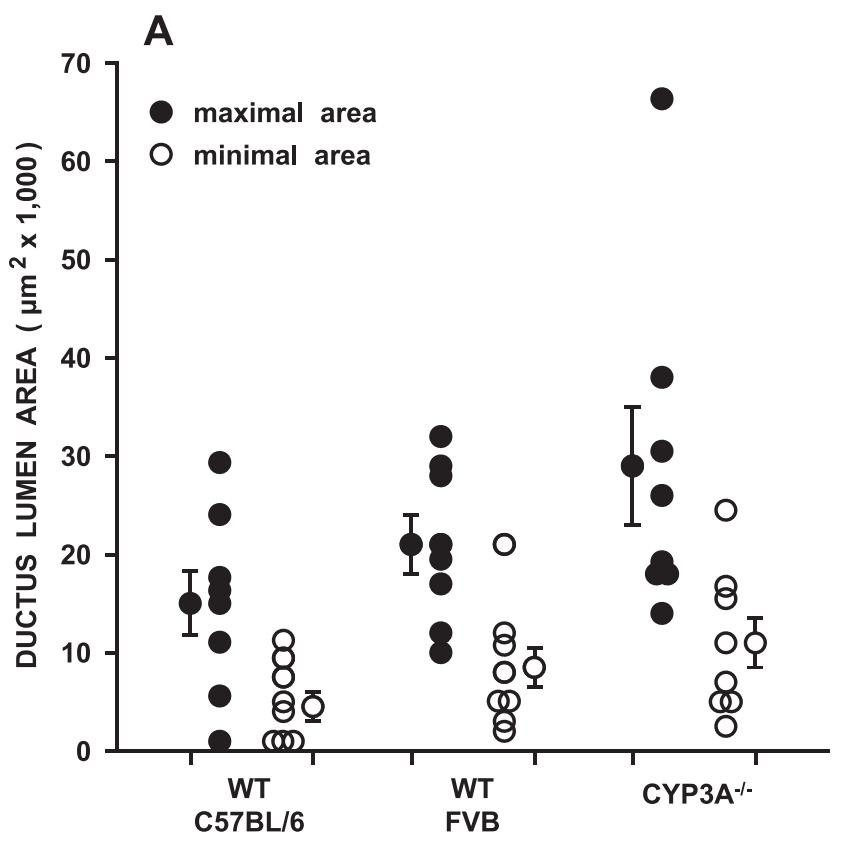

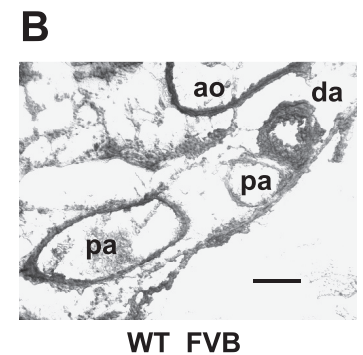

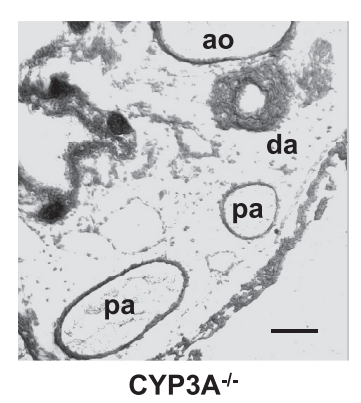

Fig. 10. Postnatal closure of DA in WT versus Cур $3 a^{-1-}$ mice. A: DA cross-sectional area for WT (C57BL/6 and FVB strains) and Cyp $3 a^{-1-}$ mice with each point applying to a different fetus. $B$ : representative sections of WT and Cyp $3 a^{-1-}$ DAs obtained at the point of maximal constriction. da, Ductus arteriosus; ao, aorta; pa, pulmonary artery. Note the smoother inner surface in Cyp $3 a^{-1-}$ compared with WT DAs. Scale bars $=150 \mu \mathrm{m}$. 
Ref. 8). A compensating mechanism was identified at the time in the withdrawal of relaxing influences responsible for DA patency in utero (8), and the same explanation may now apply to the Cyp3a $a^{-1-}$ newborn.

However well founded, our position on the role of CYP3A13 must be considered vis-à-vis another proposal ascribing sensing function to a distinct set of $\mathrm{K}_{\mathrm{v}}$ channels (i.e., $\mathrm{K}_{\mathrm{v}} 1.5$ and $\left.\mathrm{K}_{\mathrm{v}} 2.1\right)$ amenable to inhibition by oxygen $(12,23)$. Leaving aside the fact that oxygen changes may still affect muscle tone in a $\mathrm{K}^{+}$-treated vessel (25), which argues against a unique role of $\mathrm{K}^{+}$channels, we have already pointed out that these two schemes are not mutually exclusive since ET-1 can interfere with $\mathrm{K}^{+}$channel function $(8,26)$. A similar unifying position is also found in the work of Keck et al. (13), where evidence is presented of an ET-1 step preceding $\mathrm{K}^{+}$channel blockade in the oxygen activation sequence. Our present results in RA-pretreated animals shed further light on this issue. Specifically, we found that the RA-induced oxygen contraction in the Cyp $3 a^{-1-}$ DA, unlike that in the WT DA, was most of the time not inhibited by BQ-123. In our view, any such escape from ET-1 inhibition attests to the operation of an alternative, possibly $\mathrm{K}^{+}$channel-mediated, oxygen-sensing mechanism becoming prominent in response to CYP3A13 deletion. Of relevance here is the likely presence in the promoter of oxygensensitive $\mathrm{K}_{\mathrm{v}} 1.5$ and $\mathrm{K}_{\mathrm{v}} 2.1$ channels of recognition sites for a transcription factor [RA receptor/retinoid X receptor 1 (DR1)] being activated by RA (see http://www.genomatix. de). ${ }^{3}$ Hence, RA could enhance both mechanisms being proposed for oxygen sensing, but their relative importance would change depending on the state of the vessel. How this potential duality of oxygen effectors may impact on DA function remains to be ascertained. However, it could well account for the reported inconsistencies in the Cyp $3 a^{-1-}$ mutant between findings in vitro and in vivo.

In principle, a therapeutic approach promoting oxygen contraction should be superior to the currently used inhibitors of $\mathrm{PGE}_{2}$-induced relaxation in the management of prematurely born infants with a persistent DA. Any interference with $\mathrm{PGE}_{2}$ is, in fact, amenable to compensation by alternative relaxing mechanisms $(3,20,21)$. Furthermore, $\mathrm{PGE}_{2}$ itself plays a role not only in prenatal patency of the vessel but also in its closure postnatally $(16,18,28,29)$. A combination of these diverse actions likely explains the high incidence of failures with the treatment to date, which is based on cyclooxygenase inhibitors such as indomethacin or ibuprofen $(17,19)$. A better knowledge from our work of the oxygen activation sequence, and specifically of the RA role therein, opens new therapeutic prospects.

A final point, deserving a comment, relates to the abrupt maturation of the oxygen-induced contraction vis-à-vis the concomitant downregulation of the CYP3A13 transcript. RA also mimics this effect of age while promoting a full-fledged oxygen contraction. Any explanation for these findings is necessarily speculative. However, an appealing possibility is that transcript changes reflect a maturation-linked restriction of

\footnotetext{
${ }^{3}$ Recognition sites for the same transcription factor are also evident in the promoter of ECE-1 and ET-1. However, at least in the case of ET-1, any enhancing effect of RA should be exerted elsewhere (e.g., via transcript stabilization) since its mRNA expression remains unchanged throughout treatment (see Fig. 1).
}

the alleged sensor to discrete regions in DA muscle, perhaps pacemaker sites reportedly implicated in the initiation of the oxygen contraction (9).

In conclusion, we have identified the main oxygen sensor in DA with CYP3A13 and have shed light on the linkage of this hemoprotein with ET-1 in sustaining the oxygen contraction. We have also confirmed the effectiveness of RA in promoting the oxygen action, and hence its maturation through gestation, and have located in the ET-1 system, plus possibly the $\mathrm{K}^{+}$ channel oxygen-sensing mechanism, the target for the agent. These findings lend themselves to a clinical application, specifically in the development of better tools for the management of premature infants with a persistent DA. In addition, they may serve as a model for oxygen sensing elsewhere in the body.

\section{ACKNOWLEDGMENTS}

The authors thank Dr. A. H. Schinkel (Division of Experimental Therapy, The Netherlands Cancer Institute, Amsterdam, The Netherlands) for supplying the $C y p 3 a^{-1-}$ mouse strain.

\section{GRANTS}

This work was supported by Italian Ministry of Education and Research Grant PRIN 2007E7Y7R (to F. Coceani). S. Nencioni and D. Sodini are recipients of, respectively, a graduate studentship and a postdoctoral fellowship from the Scuola Superiore Sant'Anna.

\section{DISCLOSURES}

No conflicts of interest, financial or otherwise, are declared by the author(s).

\section{REFERENCES}

1. Âgren P, Cogolludo AL, Kessels CGA, Pérez-Vizcáino F, De Mey JGR, Blanco CE, Villamor E. Ontogeny of chicken ductus arteriosus response to oxygen and vasoconstrictors. Am J Physiol Regul Integr Comp Physiol 292: R485-R495, 2007.

2. Akaike T, Jin MH, Yokoyama U, Izumi-Nakaseko H, Jiao Q, Iwasaki S, Iwamoto M, Nishimaki S, Sato M, Yokota S, Kamiya Y, AdachiAkahane S, Ishikawa $\mathbf{Y}$, Minamisawa S. T-type $\mathrm{Ca}^{2+}$ channels promote oxygenation-induced closure of the rat ductus arteriosus not only by vasoconstriction but also by neointima formation. J Biol Chem 284: 24025-24034, 2009.

3. Baragatti B, Brizzi F, Barogi S, Laubach VE, Sodini D, Shesely EG, Regan RF, Coceani F. Interactions between NO, CO and an endotheliumderived hyperpolarizing factor (EDHF) in maintaining patency of the ductus arteriosus in the mouse. Br J Pharmacol 151: 54-62, 2007.

4. Baragatti B, Laniado Schwartzman ML, Angeloni D, Scebba F, Ciofini E, Sodini D, Ottaviano V, Nencioni S, Paolicchi A, Graves JP, Zeldin DC, Gotlinger K, Luin S, Coceani F. EDHF function in the ductus arteriosus: evidence against involvement of epoxyeicosatrienoic acids and $12 S$-hydroxyeicosatetraenoic acid. Am J Physiol Heart Circ Physiol 297: H2161-H2168, 2009.

5. Coceani F. Cytochrome P450 in the contractile tone of the ductus arteriosus: regulatory and effector mechanisms. In: The Fetal and Neonatal Pulmonary Circulations, edited by Weir EK, Archer SL, Reeves JT. Armonk, NY: Futura, 1999, p. 331-341.

6. Coceani F, Kelsey L. Endothelin-1 release from the lamb ductus arteriosus: are carbon monoxide and nitric oxide regulatory agents? Life Sci 66: 2613-2623, 2000.

7. Coceani F, Kelsey L, Seidlitz E. Evidence for an effector role of endothelin in closure of the ductus arteriosus at birth. Can J Physiol Pharmacol 70: 1061-1064, 1992.

8. Coceani F, Liu YA, Seidlitz E, Kelsey L, Kuwaki T, Ackerley C, Yanagisawa M. Endothelin A receptor is necessary for $\mathrm{O}_{2}$ constriction but not closure of ductus arteriosus. Am J Physiol Heart Circ Physiol 277: H1521-H1531, 1999.

9. Fay FS. Guinea pig ductus arteriosus. I. Cellular and metabolic basis for oxygen sensitivity. Am J Physiol 221: 470-479, 1971. 
10. Fay FS. Biochemical basis for response of ductus arteriosus to oxygen. In: Fetal and Neonatal Physiology, edited by Comline KS, Cross KW, Dawes GS, Nathanielsz PW. New York: Cambridge Univ. Press, 1973, p. $136-$ 140.

11. Herwaarden van AE, Wagenaar E, Kruijssen van der CMM, Waterschoot van RAB, Smit JW, Song JY, Valk van der MA, Tellingen van O, Hoorn van der JWA, Rosing H, Beijnen JH, Schinkel AH. Knockout of cytochrome P450 3A yields new mouse models for understanding xenobiotic metabolism. J Clin Invest 117: 3583-3592, 2007.

12. Kajimoto H, Hashimoto K, Bonnet SN, Haromy A, Harry G, Moudgil R, Nakanishi T, Rebeyka I, Thébaud B, Michelakis ED, Archer SL. Oxygen activates the Rho/Rho-kinase pathway and induces RhoB and ROCK-1 expression in human and rabbit ductus arteriosus by increasing mitochondria-derived reactive oxygen species: a newly recognized mechanism for sustaining ductal constriction. Circulation 115: 1777-1788, 2007.

13. Keck M, Resnik E, Linden B, Anderson F, Sukovich DJ, Herron J, Cornfield DN. Oxygen increases ductus arteriosus smooth muscle cytosolic calcium via release of calcium from inositol triphosphate-sensitive stores. Am J Physiol Lung Cell Mol Physiol 288: L917-L923, 2005.

14. Landmann L. Deconvolution improves colocalization analysis of multiple fluorochromes in 3D confocal data sets more than filtering techniques. J Microsc 208: 134-147, 2002.

15. Michelakis E, Rebeyka I, Bateson J, Olley P, Puttagunta L, Archer S. Voltage-gated potassium channels in human ductus arteriosus. Lancet 356 : 134-137, 2000.

16. Nguyen MT, Camenish T, Snouwaert JN, Hicks E, Coffman TM, Anderson PA, Malouf NN, Koller BH. The prostaglandin receptor EP 4 triggers remodelling of the cardiovascular system at birth. Nature 390: $78-81,1997$.

17. Ohlsson A, Walia R, Shah S. Ibuprofen for the treatment of patent ductus arteriosus in preterm and/or low birth weight infants (Cochrane review). In: Cochrane Database Syst Rev. Chichester, UK: Wiley, 2010, art. CD003481.

18. Reese J, Anderson JD, Brown N, Roman C, Clyman RI. Inhibition of cyclooxygenase isoforms in late- but not midgestation decreases contractility of the ductus arteriosus and prevents postnatal closure in mice. Am J Physiol Regul Integr Comp Physiol 291: R1717-R1723, 2006.

19. Shah SS, Ohlsson A. Ibuprofen for the prevention of patent ductus arteriosus in preterm and/or low birth weight infants (Cochrane review).
In: Cochrane Database Syst Rev. Chichester, UK: Wiley, 2006, art. CD004213.

20. Smith GCS. The pharmacology of the ductus arteriosus. Pharmacol Rev 50: 35-58, 1998.

21. Takizawa T, Kihara T, Kamata A. Increased constriction of the ductus arteriosus with combined administration of indomethacin and L-NAME in fetal rats. Biol Neonate 80: 64-67, 2001.

22. Taniguchi T, Azuma H, Okada Y, Naiki H, Hollenberg MD, Muramatsu I. Endothelin-1-endothelin receptor type A mediates closure of rat ductus arteriosus at birth. J Physiol 537: 579-585, 2001.

23. Thébaud B, Wu XC, Kajimoto H, Bonnet S, Hashimoto K, Michelakis ED, Archer SL. Developmental absence of the $\mathrm{O}_{2}$ sensitivity of L-type calcium channels in preterm ductus arteriosus smooth muscle cells impairs $\mathrm{O}_{2}$ constriction contributing to patent ductus arteriosus. Pediatr Res 63: 176-181, 2008.

24. Wang Y, Mercer-Connolly A, Lines L, Toyoda O, Coceani F. Endothelium-denuded pulmonary resistance arteries from the fetal lamb: preparation and response to vasoactive agents. J Pharmacol Toxicol Methods 32: 85-91, 1994.

25. Weir EK, López-Barneo J, Buckler KJ, Archer SL. Acute oxygensensing mechanisms. N Engl J Med 353: 2042-2055, 2005.

26. Whitman EM, Pisarcik S, Luke T, Fallon M, Wang J, Sylvester JT, Semenza GL, Shimoda LA. Endothelin-1 mediates hypoxia-induced inhibition of voltage-gated $\mathrm{K}^{+}$channel expression in pulmonary arterial myocytes. Am J Physiol Lung Cell Mol Physiol 294: L309-L318, 2008.

27. Wu GR, Jing S, Momma K, Nakanishi T. The effect of vitamin A on contraction of the ductus arteriosus in fetal rat. Pediatr Res 49: 747-754, 2001.

28. Yokoyama U, Minamisawa S, Quan H, Akaike T, Suzuki S, Jin M, Jiao Q, Watanabe M, Otsu K, Iwasaki S, Nishimaki S, Sato M, Ishikawa Y. Prostaglandin $\mathrm{E}_{2}$-activated Epac promotes neointimal formation of the rat ductus arteriosus by a process distinct from that of cAMP-dependent protein kinase A. J Biol Chem 283: 28702-28709, 2008.

29. Yokoyama U, Minamisawa S, Quan H, Ghatak S, Akaike T, SegiNishida E, Iwasaki S, Iwamoto M, Misra S, Tamura K, Hori H, Yokota S, Toole BP, Sugimoto Y, Ishikawa Y. Chronic activation of the prostaglandin receptor $\mathrm{EP}_{4}$ promotes hyaluronan-mediated neointimal formation in the ductus arteriosus. J Clin Invest 116: 3026-3034, 2006. 